\title{
Solar particle effects on minor components of the Polar atmosphere
}

\author{
A. Damiani ${ }^{1,2}$, M. Storini ${ }^{2}$, M. Laurenza ${ }^{2}$, and C. Rafanelli ${ }^{1}$ \\ ${ }^{1}$ ICES - International Center for Earth Sciences c/o CNR Istituto di Acustica "O.M. Corbino" - Area di Ricerca Roma-Tor \\ Vergata, Via del Fosso del Cavaliere, 100-00133 Roma, Italy \\ ${ }^{2}$ Istituto di Fisica dello Spazio Interplanetario - INAF - Area di Ricerca Roma-Tor Vergata, Via del Fosso del Cavaliere, \\ 100-00133 Roma, Italy
}

Received: 1 February 2007 - Revised: 14 August 2007 - Accepted: 14 August 2007 - Published: 26 February 2008

\begin{abstract}
Solar activity can influence the Earth's environment, and in particular the ozone layer, by direct modulation of the e.m. radiation or through variability of the incoming cosmic ray flux (solar and galactic particles). In particular, solar energetic particles (SEPs) provide additional external energy to the terrestrial environment; they are able to interact with the minor constituents of the atmospheric layer and produce ionizations, dissociations, dissociative ionizations and excitations. This paper highlights the SEP effects on the chemistry of the upper atmosphere by analysing some SEP events recorded during 2005 in the descending phase of the current solar cycle. It is shown that these events can lead to short- (hours) and medium- (days) term ozone variations through catalytic cycles (e.g. $\mathrm{HO}_{\mathrm{x}}$ and $\mathrm{NO}_{\mathrm{x}}$ increases). We focus attention on the relationship between ozone and $\mathrm{OH}$ data (retrieved from MLS EOS AURA) for four SEP events: 17 and 20 January, 15 May and 8 September. We confirm that SEP effects are different on the night and day hemispheres at high latitudes.
\end{abstract}

Keywords. Atmospheric composition and structure (Ion chemistry of the atmosphere) - Interplanetary physics (Energetic particles) - Ionosphere (Polar ionosphere)

\section{Introduction}

Energetic charged particles coming from the Sun are able to produce ionization at different altitudes of the terrestrial atmosphere. They can initiate catalytic cycles for ozone depletion, involving $\mathrm{NO}_{\mathrm{x}}\left(\mathrm{N}, \mathrm{NO}, \mathrm{NO}_{2}\right)$ and $\mathrm{HO}_{\mathrm{x}}\left(\mathrm{H}, \mathrm{OH}, \mathrm{HO}_{2}\right)$ components (see Crutzen et al., 1975; Solomon et al., 1981a).

Many past works were devoted to the investigation of the effects of intense SEP (solar energetic particle) events on the

Correspondence to: A. Damiani

(alessandro.damiani@idac.rm.cnr.it) terrestrial ozone layer (e.g. Reagan et al., 1981, for the August 1972 SEP event; Solomon et al., 1983, for July 1982; Reid et al., 1991, and Jackman et al., 1995, for October 1989, among others). The atmospheric ozone variation related to the incoming solar proton flux has been explained and described both by models and satellite data, while the increase in odd nitrogen and hydrogen species during and after a SEP event has only been studied by models, due to the lack of data. Moreover, almost all of the past instruments were not able to determine the ozone concentration without the solar light and that prevented the check of the accuracy of available models for the night hemisphere. Finally, it has been possible to compare chemical models involving atmospheric minor components with satellite data only during the last decade.

During the SEP event of July 2000 (see Krivolutsky et al., 2006, for a recent review), for the first time, the contemporary availability of $\mathrm{O}_{3}$ and $\mathrm{NO}_{\mathrm{x}}$ data has shown the reliability of the models in use (Jackman et al., 2001). Afterwards, when in late October 2003 a series of intense SEP events occurred (and new instruments were operating on board satellites) interesting features related to SEP effects on the terrestrial atmosphere were pointed out (Jackman et al., 2005; Seppälä et al., 2004; Rohen et al., 2005; López-Puertas et al., 2005a; Verronen et al., 2005, and references therein). Moreover, thanks to the new instruments the analyses were also extended to other retrieved chemical parameters (e.g. $\mathrm{HNO}_{3}$, $\mathrm{N}_{2} \mathrm{O}_{5}, \mathrm{ClONO}_{2}$; see López-Puertas et al., 2005b; Orsolini et al., 2005).

Concerning the SEP effects on the ozone layer, the principal lack of atmospheric chemistry observations prior to the middle of 2004 was related to odd hydrogen species. For this reason, in this paper we selected some SEP events that occurred in 2005, namely 17 and 20 January, 15 May and 8 September.

The study of January 2005 SEPs is relevant since, for the first time, a satellite instrument was able to register the

Published by Copernicus Publications on behalf of the European Geosciences Union. 
rise of $\mathrm{HO}_{\mathrm{x}}$ during the solar particle flux hitting the Earth's atmosphere on 17 and 20 January. Verronen et al. (2006) demonstrated that the OH rise (measured by the MLS EOS instrument on the AURA satellite) and the ozone depletion (measured by the Gomos instrument on the Envisat satellite) were in good agreement with model expectations for 18 and 20 January at $69^{\circ}-70^{\circ} \mathrm{N}$ at twilight condition. Moreover, Damiani et al. (2007) ${ }^{1}$ highlights that the $\mathrm{OH}$ rise, averaged at $82^{\circ} \mathrm{N}$ and $0.1 \mathrm{hPa}(\sim 64 \mathrm{~km})$ with the same solar zenith angle (SZA $\sim 108^{\circ} / \mathrm{LST}: 7.67 \mathrm{~h}$, to avoid daily variability), increased by hundreds of percent on 18 January (less on 20 January), although the same violent rise did not appear in the equivalent location of the Southern Hemisphere. The reason for this behaviour can be explained by taking into account the $\mathrm{OH}$ concentration in the mesosphere. The main reservoir of mesospheric odd hydrogen species is the water vapour that exhibits a strong seasonal cycle, with summer concentrations [ $\sim 8 \mathrm{ppmv}]$ higher than in winter [ 1 ppmv] (Hervig et al., 2003). In the lower mesosphere and stratosphere the main $\mathrm{OH}$ source is the reaction of water vapour with metastable oxygen $\mathrm{O}\left({ }^{1} \mathrm{D}\right)$. In the upper mesosphere the main $\mathrm{OH}$ source is water photolysis. Therefore, in the night hemisphere, near polar night termination, the low water vapour and $\mathrm{O}\left({ }^{1} \mathrm{D}\right)$ content and the weak photolysis process lead to a weak background concentration of OH (see Crutzen, 1997; Seppälä et al., 2006; Canty et al., 2006); it follows that the abrupt rise associated with the solar particle flux can be easily identified. In the day hemisphere, however, the high background of $\mathrm{HO}_{\mathrm{x}}$ may hide the increase induced by the SEPs.

\section{Atmospheric data}

The data used in this work were recorded by the Microwave Limb Sounder (MLS) instrument on the AURA satellite (Schoeberl et al., 2006). The NASA EOS (Earth Observing System) MLS (see Waters et al., 2006) is one of the four instruments of AURA launched on 15 July 2004 to a sunsynchronous near polar orbit. MLS scans the Earth's limb in the forward direction of flight with a vertical resolution of about $3 \mathrm{~km}$, viewing the microwave emission in different spectral regions. The measured chemical components are: $\mathrm{O}_{3}, \mathrm{H}_{2} \mathrm{O}, \mathrm{BrO}, \mathrm{ClO}, \mathrm{HCl}, \mathrm{HOCl}, \mathrm{OH}, \mathrm{HO}_{2}, \mathrm{HCN}, \mathrm{CO}$, $\mathrm{HNO}_{3}, \mathrm{~N}_{2} \mathrm{O}$, and $\mathrm{SO}_{2}$ mixing ratios (see Froidevaux et al., 2006, for early validation analyses). In this work we will focus on the $\mathrm{O}_{3}$ and OH EOS MLS Version 1.5 Level 2 Data (available at http://mls.jpl.nasa.gov/data/).

The MLS instrument measures the $\mathrm{OH}$ mixing ratio during day and night conditions by thermal emission over the range 18-94 km. Unfortunately, Pickett et al. (2006) point out that the version 1.51 of MLS OH values can be used only between $\sim 30$ and $\sim 60 \mathrm{~km}$, because of a systematic error at

\footnotetext{
${ }^{1}$ Damiani, A., Storini, M., Laurenza, M., et al.: Search for the ozone variability related to SEP events during the current solar cycle, Adv. Space Res., submitted, 2007.
}

higher altitudes which could be produced by a regular bias or an offset in the data. Nevertheless, in order to single out the SEP effects on the atmospheric components, MLS data can be used at least for the evaluation of a qualitative answer. In addition, we improved the data quality by the averaging procedure of different profiles, being the random error reduced by the mathematical approach. Moreover, the MLS ozone data version 1.51 also showed good reliability in the stratosphere but a decreased precision in the mesosphere (see Froidevaux et al., 2006).

The MLS data used in this paper were checked by their data quality and description document (Livesey et al., 2005), in order to ensure the reliability of our results. In addition, the $\mathrm{OH}$ data were further processed by checking their trend at each altitude level to delete a few spurious spikes that were randomly distributed in time. About 250 profiles per day were available in the selected latitude intervals $\left(75^{\circ}-82^{\circ}\right)$. In all the following figures the atmospheric data trends are presented as running averages of the real data, calculated on roughly 200 profiles.

The standard deviation (SD) for the $\mathrm{O}_{3}$ profiles is roughly $5-10 \%$ for the stratosphere and 15-30 (50)\% for the mesosphere in the night (day) hemisphere. The SD for the $\mathrm{OH}$ profiles is roughly $30 \%$ in the mesosphere and $20(>50) \%$ in the stratosphere on the day (night) hemisphere. As expected, if the component concentration is low the uncertainty increases.

\section{SEP events}

A description of the most powerful SEP events recorded in 2005 is given in the following. We analyzed soft Xray measurements $(1-8 \AA)$ and proton flux data at energies $>10 \mathrm{MeV},>50 \mathrm{MeV},>100 \mathrm{MeV}$ from the GOES satellite series, available at the web site http://www.ngdc.noaa.gov/ stp/GOES/goes.html. In order to define a proton enhancement as a SEP event, we required the proton flux at energies $>10 \mathrm{MeV}$ to be greater than the standard NOAA threshold of $10 \mathrm{pfu}\left(1 \mathrm{pfu}=\right.$ particle $\left./\left(\mathrm{cm}^{2} \mathrm{~s} \mathrm{sr}\right)\right)$. Nevertheless, we required this condition to be satisfied for at least one hour (see Laurenza et al., 2007). Table 1 summarizes the key properties of the selected SEP events, which, for convenience, are referred to by number as events 1 to 4 : date and time of the SEP maximum intensity at $>10 \mathrm{MeV}$, the peak flux value and fluence (both computed on hourly basis) for all the energy channels and the total duration, i.e. the time interval $(\Delta)$ between the onset time of the SEP event and its end. The maximum proton intensity and fluence were obtained from hourly averages of 5-min raw data. We considered as the start of a SEP event the first of 3 consecutive 5-min data points with fluxes $\geq 10 \mathrm{pfu}$. The end of an event is the last time the flux was $\geq 10$ pfu if no new injections follow the event; otherwise, the end of the previous event is set at the point preceding the successive increase. Table 1 also includes the characteristics of 
Table 1. Characteristic parameters for the considered SEP events (see the text for details). Date and Time for each SEP event refer to the maximum flux value at $>10 \mathrm{MeV}$.

\begin{tabular}{|c|c|c|c|c|c|c|c|c|c|c|}
\hline \multicolumn{7}{|c|}{ SEP event } & \multicolumn{4}{|c|}{ Associated flare } \\
\hline Label & Date & $\begin{array}{l}\text { Time } \\
{[\mathrm{UT}]}\end{array}$ & $\begin{array}{l}\text { Energy } \\
{[\mathrm{MeV}]}\end{array}$ & $\begin{array}{l}\text { Peak flux } \\
\text { [pfu] }\end{array}$ & $\begin{array}{c}\text { Fluence } \\
\left.\left[\text { part./(} \mathrm{cm}^{2} \mathrm{sr} \times 3600\right)\right]\end{array}$ & $\begin{array}{c}\Delta \\
{[\mathrm{d}]}\end{array}$ & Date & $\begin{array}{l}\text { Time } \\
\text { [UT] }\end{array}$ & $\begin{array}{l}\text { X-ray } \\
\text { class }\end{array}$ & $\begin{array}{c}\mathrm{H} \alpha \\
\text { location }\end{array}$ \\
\hline 1 & 17 Jan 2005 & $17: 30$ & $\begin{array}{c}>10 \\
>50 \\
>100\end{array}$ & $\begin{array}{l}4.13 \times 10^{3} \\
3.33 \times 10^{2} \\
2.59 \times 10^{1}\end{array}$ & $\begin{array}{l}5.61 \times 10^{4} \\
3.98 \times 10^{3} \\
2.99 \times 10^{2}\end{array}$ & 2.76 & 17 Jan & 09:52 & $\mathrm{X} 4.2$ & N14W24 \\
\hline 2 & 20 Jan 2005 & 08:30 & $\begin{array}{c}>10 \\
>50 \\
>100\end{array}$ & $\begin{array}{l}1.42 \times 10^{3} \\
9.39 \times 10^{2} \\
4.89 \times 10^{2}\end{array}$ & $\begin{array}{l}1.72 \times 10^{4} \\
5.05 \times 10^{3} \\
1.88 \times 10^{3}\end{array}$ & 2.45 & $20 \mathrm{Jan}$ & 07:00 & X 7.9 & N12W58 \\
\hline 3 & 15 May 2005 & 03:30 & $\begin{array}{c}>10 \\
>50 \\
>100\end{array}$ & $\begin{array}{l}1.90 \times 10^{3} \\
0.58 \times 10^{0} \\
0.14 \times 10^{0}\end{array}$ & $\begin{array}{c}7.98 \times 10^{3} \\
1.07 \times 10 \\
2.11 \times 10^{0}\end{array}$ & 1.05 & 13 May & $16: 57$ & M8.5 & $\mathrm{N} 12 \mathrm{E} 12$ \\
\hline 4 & $11 \mathrm{Sep} 2005$ & 04:30 & $\begin{array}{l}>10 \\
>50 \\
>100\end{array}$ & $\begin{array}{l}1.88 \times 10^{3} \\
5.10 \times 10^{1} \\
7.63 \times 10^{0}\end{array}$ & $\begin{array}{l}4.57 \times 10^{4} \\
2.09 \times 10^{3} \\
3.52 \times 10^{2}\end{array}$ & 4.81 & $7 \mathrm{Sep}$ & $17: 40$ & $\mathrm{X} 17$ & S06E89 \\
\hline
\end{tabular}

each SEP associated flare, taken from the database described by Laurenza et al. (2007).

Figure 1 shows the time-intensity profiles of the soft Xray and the proton fluxes, in the three considered energy intervals, for all the selected events. Top panel of Fig. 1 illustrates these quantities during the period 15-22 January: a $>10 \mathrm{MeV}$ proton (black line) enhancement began on 15 January, but without exceeding the threshold of $10 \mathrm{pfu}$. A first SEP event began on 16 January at 02:10 UT, but the two largest SEPs occurred on consecutive days, reaching their maximum intensity on 17 January at 17:30 UT (value of $4.13 \times 10^{3} \mathrm{pfu}$ at $>10 \mathrm{MeV}$ ) and on 20 January at 08:30 UT (value of $1.42 \times 10^{3} \mathrm{pfu}$ at $>10 \mathrm{MeV}$ ); they were associated with an X4.2 flare on 17 January (09:52 UT) and an X7.9 flare on 20 January (07:00 UT), respectively; both originated in solar region NOAA 720 (when it was located in the Western Hemisphere at $24^{\circ} \mathrm{W}$ and $58^{\circ} \mathrm{W}$, i.e. magnetically wellconnected to Earth). These flares were also accompanied by Type II and Type IV radio bursts and coronal mass ejections (CMEs). Moreover, protons at high energy levels of $>50 \mathrm{MeV}$ (red line) and $>100 \mathrm{MeV}$ (green line) rose rapidly (see upper panel of Fig. 1); an intense ground level enhancement (GLE) immediately followed the last infusion of high energetic protons and was observed by the world-wide network of neutron monitors. The period ended with protons in a gradual decline.

Another SEP event was observed on 14 May with onset time at 05:25 UT and a $>10 \mathrm{MeV}$ peak value of $1.90 \times 10^{3}$ pfu on 15 May at 03:30 UT (middle panel of Fig. 1), following the CME shock arrival. It was associated with the M8.5 flare on 13 May at 16:57 UT, produced in the active region NOAA 759 along with Type II and Type IV radio sweeps, as well as a bright full halo CME. Nevertheless, the contribution of the most energetic protons is very small, with maximum flux values of $0.58 \mathrm{pfu}$ and $0.14 \mathrm{pfu}$ at $>50 \mathrm{MeV}$ and $>100 \mathrm{MeV}$, respectively.

NOAA region 808 produced a major X17 proton flare, peaking at 17:40 UT on 7 September. Strong Type II and IV radio sweeps and a very large and fast CME were recorded and an intense proton storm at $>10 \mathrm{MeV}$ started at Earth on 8 September at 02:15 UT with a maximum on 11 September at 04:30 UT. The SEP intensification also includes high energy protons up to $>100 \mathrm{MeV}$ (peak value $7.63 \mathrm{pfu}$ ), despite the location of the solar source $\left(89^{\circ} \mathrm{E}\right)$. As a matter of fact, it is extremely rare to see $100 \mathrm{MeV}$ protons from a source on or near the east limb. However, we should note that the period with enhanced particle flux contains a large series of X-class bursts, which were not separated.

We point out that the considered SEP events present very different characteristics between each other. SEP 1 has the highest flux and fluence at $10 \mathrm{MeV}$, although it has a shorter duration than the longest one, namely SEP 4 ( $2.76 \mathrm{~d}$ and $4.81 \mathrm{~d}$, respectively). Moreover, it has a minor content of very high energies relative to SEP 2, which turned out to be a GLE, where the rise in the three different energy ranges is also simultaneous. Finally, SEP 3 has the shortest duration $(1.05 \mathrm{~d})$ and smallest fluence at all energies.

\section{The ozone}

Figure 2 displays the ozone mixing ratio in the Northern and Southern Hemisphere, evaluated in the altitude range of 

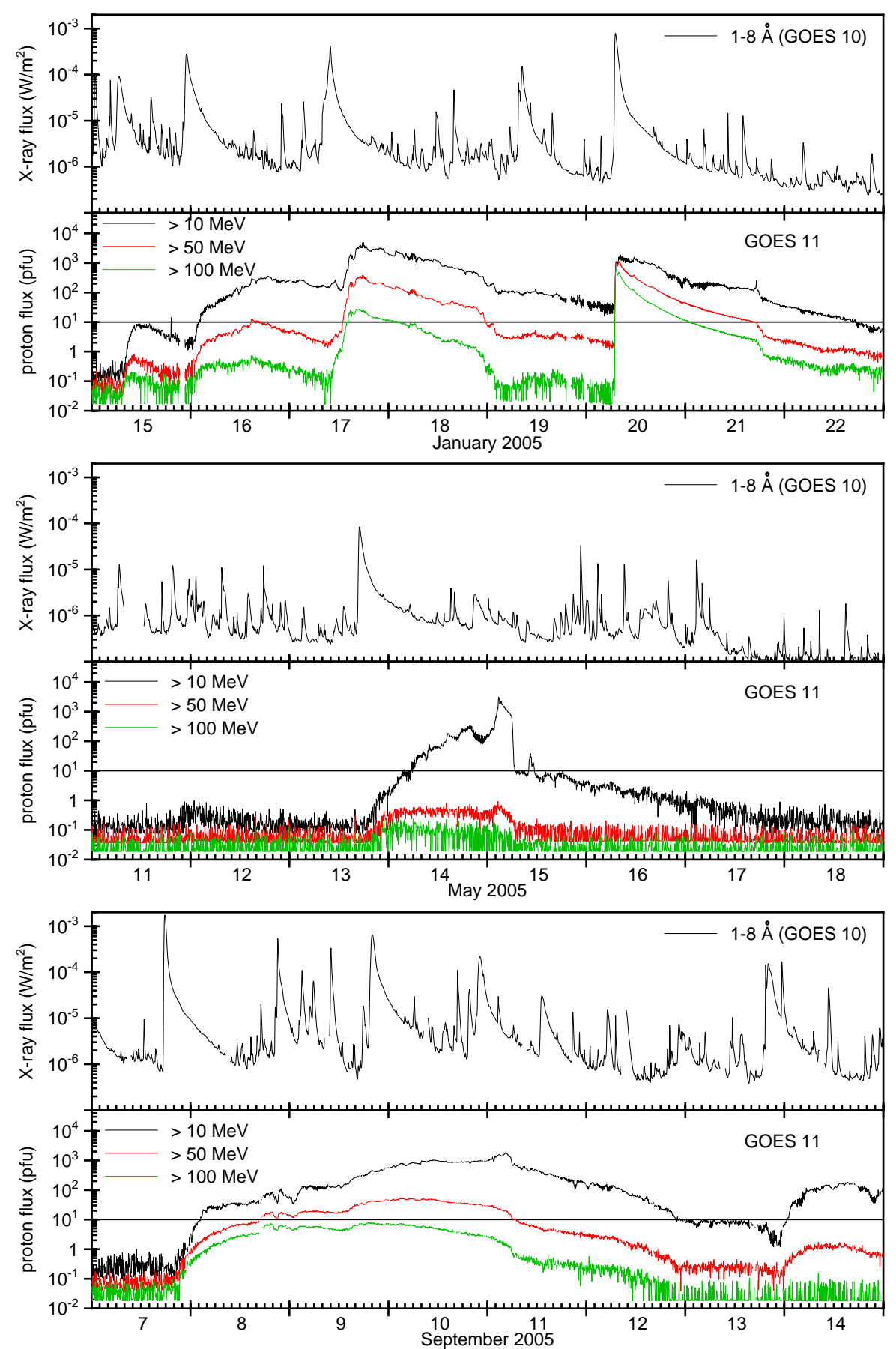

Fig. 1. Time-intensity profiles of the soft X-ray and the proton fluxes in several energy intervals $(>10,>50,>100 \mathrm{MeV})$, for all the selected events.

$\sim 20-75 \mathrm{~km}$. The panels on the left side show ozone data collected in the Northern Hemisphere roughly between $75^{\circ}-82^{\circ}$ geographic latitude and, on the right side, the data for the South side in the same range of latitude. From top to bottom it is possible to follow the ozone concentration during: 15-31 January, 10-25 May and 4-16 September 2005. As expected, there is large ozone variability in the mesosphere and stratosphere which depends on the different seasons involved. Overall, a high (low) ozone mixing ratio is present in the summer stratosphere (mesosphere) and a low (high) one in the winter time. The existence of a mesospheric ozone maximum at about $70 \mathrm{~km}$, before the occurrence of the SEP 

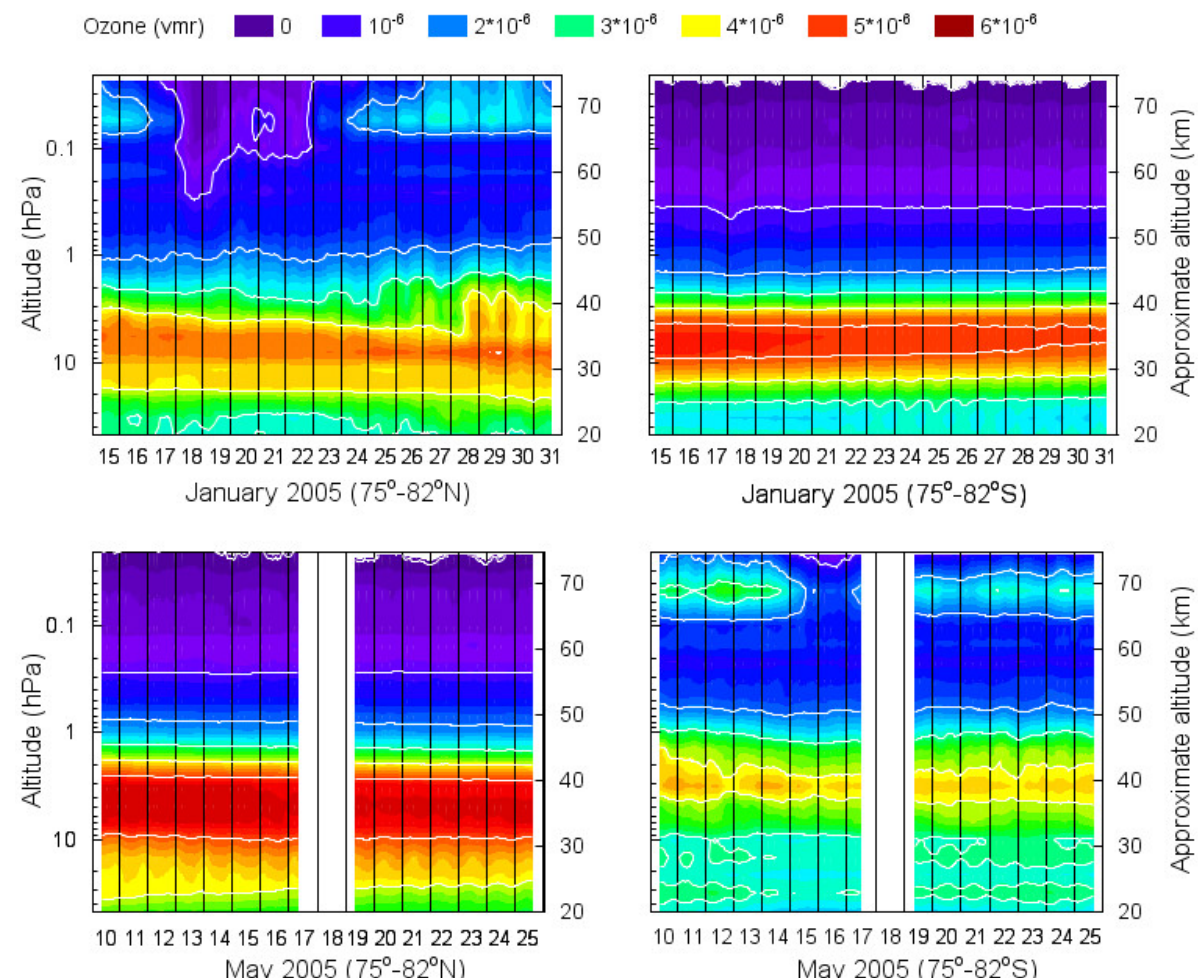

May $2005\left(75^{\circ}-82^{\circ} \mathrm{S}\right)$
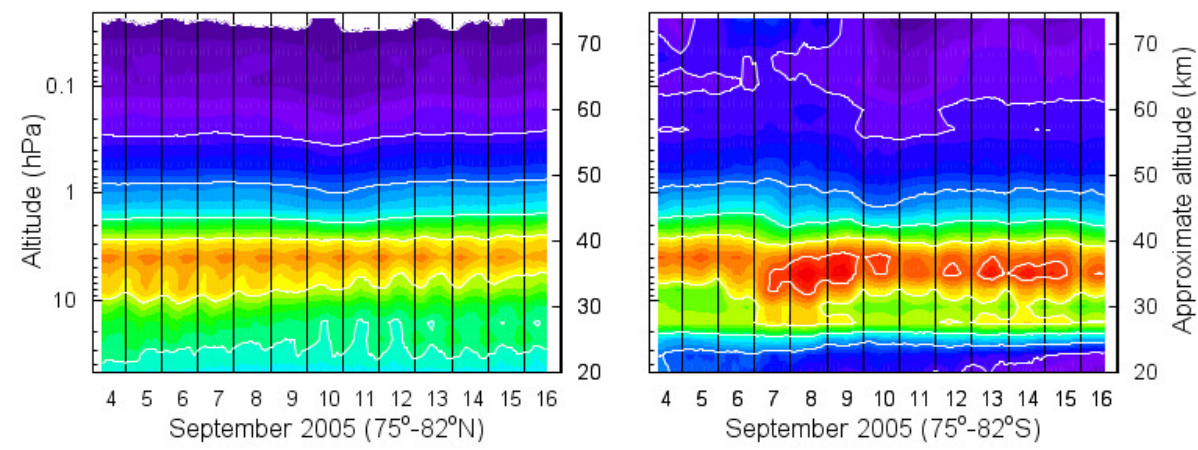

Fig. 2. Temporal evolution of averaged values $\left(\sim 75^{\circ}-82^{\circ} \mathrm{N}\right.$ and $\left.\mathrm{S}\right)$ of atmospheric $\mathrm{O}_{3}$ volume mixing ratio (vmr) for the investigated 2005 SEP events: (top) January, at North $93^{\circ}<\mathrm{SZA}<118^{\circ}$ and at South $61^{\circ}<\mathrm{SZA}<87^{\circ}$; (middle) May, at North $56^{\circ}<\mathrm{SZA}<80^{\circ}$ and at South $99^{\circ}<\mathrm{SZA}<123^{\circ}$; (bottom) September, at North $68^{\circ}<\mathrm{SZA}<94^{\circ}$ and at South $85^{\circ}<\mathrm{SZA}<111^{\circ}$. The left column reports the Northern Hemisphere and the right the Southern Hemisphere.

events, appears clearly at least in January and May 2005 (note that also in September, in the Southern Hemisphere springtime -, the mesospheric ozone mixing ratio seems to be higher than the one for the Northern Hemisphere).

In the mesosphere the ozone concentration is mainly a function of the effectiveness of catalytic cycles involving $\mathrm{HO}_{\mathrm{x}}$ components. Moreover, above approximately $70 \mathrm{~km}$ the main source of odd hydrogen species is the photolysis of $\mathrm{H}_{2} \mathrm{O}$, especially by the absorption of Lyman-alpha radiation (Crutzen, 1997). Therefore, in the upper mesosphere-lower thermosphere (roughly above $90 \mathrm{~km}$ ) the presence of a secondary ozone maximum can be explained by the decrease in photolysed $\mathrm{H}_{2} \mathrm{O}$ which leads to the ozone rise further enhanced by thermospheric atomic oxygen.
In a similar way it is possible to explain the existence of the so-called "third ozone maximum" (Marsh et al., 2001; Degenstein et al., 2005) in the mesospheric winter hemisphere at high latitudes and at about $72 \mathrm{~km}$ of altitude. In fact, during the night state, the reduced production of $\mathrm{HO}_{\mathrm{x}}$ components (see Introduction) facilitates the increase in the ozone concentration, but during the "day" such an increase is prevented.

The presence of the third ozone maximum in the winter hemisphere makes it easier to highlight the ozone concentration variability related to solar particle events. For example, Seppälä et al. (2006) showed, by using Gomos data, the destruction of this third ozone maximum during the January 2005 SEP events in the geographic latitudinal 

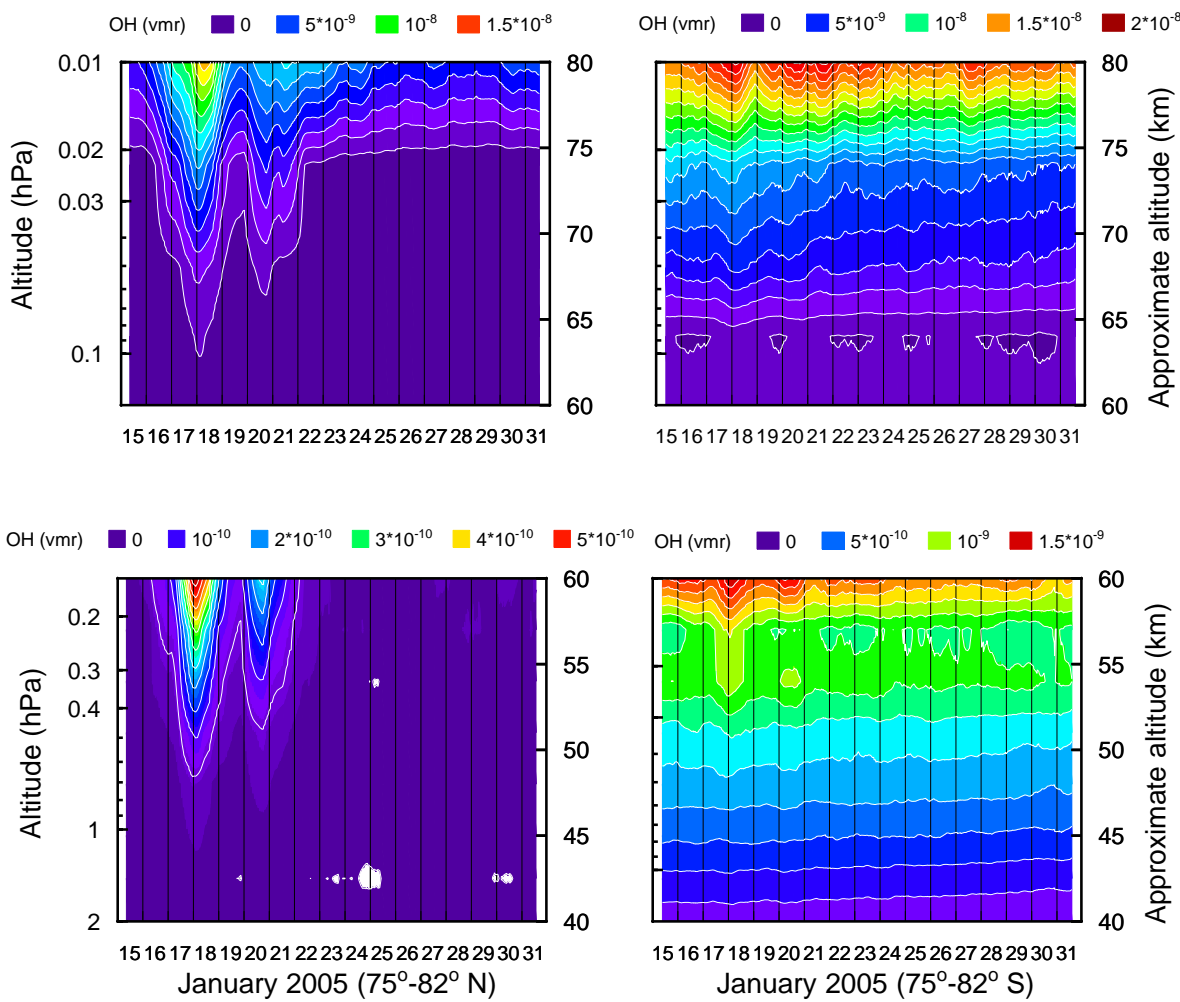

Fig. 3. Temporal evolution of averaged values $\left(\sim 75^{\circ}-82^{\circ} \mathrm{N}\right.$ and $\left.\mathrm{S}\right)$ of January $2005 \mathrm{OH}$ volume mixing ratio (vmr), approximately in mesosphere (top) and in upper stratosphere (bottom). The left column reports the Northern Hemisphere and the right the Southern one (see the caption of Fig. 2 for the correspondent SZA).

band $65^{\circ}-75^{\circ}$ N. Our Fig. 2 (top left) highlights that also at $75^{\circ}-82^{\circ} \mathrm{N}$ the third ozone peak (more than $2 \mathrm{ppmv}$ ) was destroyed. The mesospheric ozone depletion seems to persist from 17 to 23 January with a maximum intensity and vertical extension during 18 January. A secondary maximum depletion appears roughly from the end of 20 January to the middle of 21 January. Because of minor proton fluxes at lower energies (hitting the high Earth's atmosphere) for the 20 January SEP event in comparison to the 17 (see Fig. 1 and Table 1), the effects on the mesosphere are more limited (however, as noted in the previous section, the 20 January SEP event reached relativistic energies and stratospheric effects cannot be excluded). Moreover, our analysis, carried out with atmospheric conditions similar to the ones considered by Seppälä et al. (2006), showed a good agreement of the EOS MLS data with those from Gomos stellar occultation; this suggests the reliability of our data set for this kind of studies. Nevertheless, the mesospheric ozone depletion derived from the MLS instrument in the range $65^{\circ}-75^{\circ} \mathrm{N}$ is less intense than the one for $75^{\circ}-82^{\circ} \mathrm{N}$ (this work). The study of the ozone variability in the latter case shows that the ozone depletion (Fig. 2, top left) is mainly related to the odd hydrogen rise until about $1 \mathrm{hPa}$ (see also Fig. 3), in agreement with past studies (see Lary, 1997) and observable results (Rohen et al., 2005).
At lower altitudes (stratosphere) theory suggests long lasting ozone depletion connected to the odd nitrogen species rise (see Lary, 1997; Jackman et al., 2005). A decrease in the stratospheric ozone is present in the MLS January 2005 data but it seems to start before the 17 January SEP event (see also Fig. 4 of Seppälä et al., 2006), although an increment in the depletion appears after the 20 January GLE. Moreover, Damiani et al. $(2007)^{1}$ show an increase in $\mathrm{HNO}_{3}$ at about $1 \mathrm{hPa}$ and $82^{\circ} \mathrm{N}$, probably due to the rise in $\mathrm{HO}_{\mathrm{x}}$ and/or $\mathrm{NO}_{\mathrm{x}}$. Hence, the $\mathrm{NO}_{\mathrm{x}}$ should be responsible for a weak stratospheric ozone depletion, since it is in the night state $\left(\mathrm{SZA}>93^{\circ}\right)$, with the catalytic cycle for the ozone destruction (involving odd nitrogen) not very efficient due to the lack of sunlight.

The condition of the Southern Hemisphere is very different during January 2005 (Fig. 2, top right). First of all, the poor concentration of ozone in the mesosphere makes it difficult to clearly identify an ozone decrease. Nevertheless, it is possible to note a weak ozone decrease at about $0.1 \mathrm{hPa}$, as well as in the stratosphere during the 17 and 20 January SEP events. This is in agreement with the short depletion $(<12 \mathrm{~h})$ found by Damiani et al. (2006) at the edge of the polar region of the Southern Hemisphere by using SAGE II and POAM III data. 

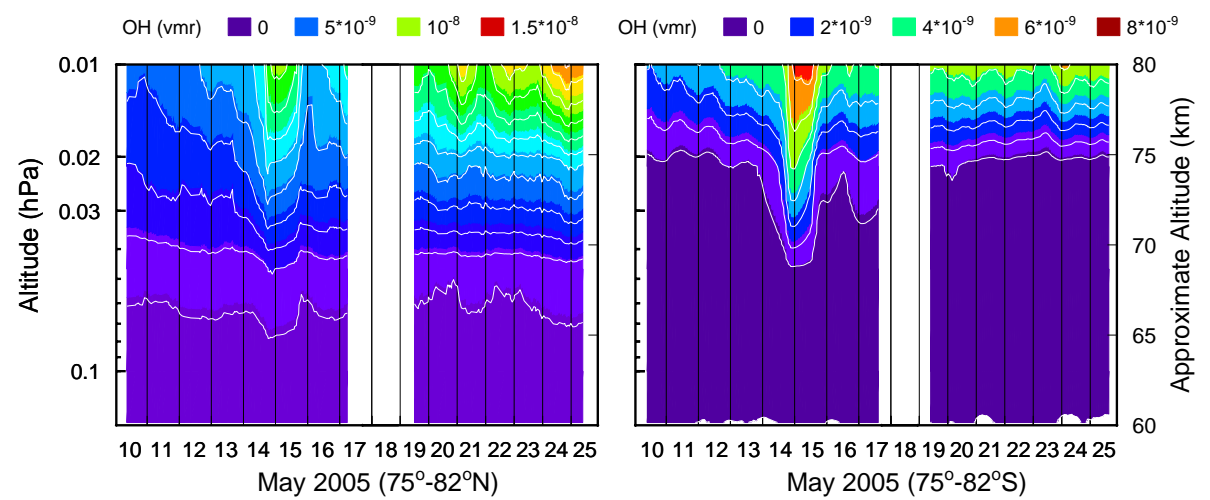

Fig. 4. Temporal evolution of averaged values $\left(\sim 75^{\circ}-82^{\circ} \mathrm{N}\right.$ and $\left.\mathrm{S}\right)$ of May $2005 \mathrm{OH}$ volume mixing ratio (vmr), approximately in mesosphere, in the Northern Hemisphere (left) and Southern one (right) (see the caption of Fig. 2 for the correspondent SZA).

Results for the SEP event of 15 May 2005 are quite similar (see Fig. 2, middle panels and Fig. 4). In the night hemisphere (South side, $\mathrm{SZA}>99^{\circ}$ ) the presence of the third ozone peak can be seen. After the arrival of the solar protons to the Earth's atmosphere and the starting of $\mathrm{HO}_{\mathrm{x}}$ catalytic cycles, the third ozone peak is destroyed at least during 16 May and much of 15 and 17 May. No EOS MLS data were available for 18 May but we note the reformation of a less intense ozone peak starting from 19 May. In the stratosphere feeble ozone depletion can be noted at altitudes of about $50 \mathrm{~km}$, although the May 2005 SEP event was not so intense as other SEPs studied in the past and the darkness of the Southern Hemisphere may suggest no effectiveness of the $\mathrm{NO}_{\mathrm{x}}$ catalytic cycle of ozone destruction.

The trend of the ozone during the investigated period can be highlighted as follows: the first one, in the mesosphere (already described) and the second one, in the stratosphere, that starts on 14 May and lasts up to few days after the recovery of the mesospheric depletion. The latter does not seem to be due to the $\mathrm{HO}_{\mathrm{x}}$ rise (see Fig. 4 for the $\mathrm{OH}$ variation in the mesosphere) because of the low altitude and the difference relative to the mesospheric depletion. As pointed out by Lary (1997) the effectiveness of the $\mathrm{NO}_{\mathrm{x}}$ catalytic cycle is maximum at about $45 \mathrm{~km}$ and, for this reason, it is possible to distinguish a different trend of depletion roughly above and below $50 \mathrm{~km}$ (see also Rohen et al., 2005). In the day hemisphere $\left(65^{\circ}<\mathrm{SZA}<80^{\circ}\right)$ no effects on the ozone layer can be detected.

The last two ozone temporal evolutions of Fig. 2 (bottom panels), related to the 8 September 2005 SEP event, seem to confirm the interpretation of the previous SEP effects. We note that in September the solar light is fairly similar in both hemispheres. In particular, the solar zenith angle of the satellite's measurements is: $68^{\circ}<\mathrm{SZA}<94^{\circ}$ for the north side and $85^{\circ}<\mathrm{SZA}<111^{\circ}$ for the south; that is the reason of the roughly similar atmospheric response to solar protons. However, for the darker hemisphere (South) the mesospheric ozone depletion is more evident, since the ozone mixing ra- tio, before the SEP event, is more elevated than for the Northern Hemisphere. Also in the stratosphere the depletion is more evident and long lasting in the Southern Hemisphere. The maximum ozone decrease occurs on 10 September in both hemispheres.

\section{The hydroxyl radical}

The following figures confirm past model results regarding the rise of odd hydrogen species during a SEP event. Moreover, it is illustrated that not only the stronger SEP events influence the Earth's atmospheric chemistry.

Figures 3, 4 and 5 show the response of the hydroxyl radical to the considered 2005 SEP events. The Northern Hemisphere is shown in the left column and the Southern Hemisphere in the right. In Figs. 3 and 5 the time history of the data is shown in two different altitude ranges for each hemisphere (roughly $40-60 \mathrm{~km}$ at the top and $60-80 \mathrm{~km}$ at the bottom), since there is a difference of about an order of magnitude on the $\mathrm{OH}$ mixing ratio between the mesosphere and the upper stratosphere (note the different $\mathrm{OH}$ colour scale). Figure 4 shows only the high altitude range because negligible stratospheric effects were found for the 14 May 2005 SEP event.

It is important to recall that the main source of $\mathrm{OH}$ radicals is water vapour photolysis and $\mathrm{O}\left({ }^{1} \mathrm{D}\right)$ oxidation of hydrogens $\mathrm{H}_{2}$ and $\mathrm{H}_{2} \mathrm{O}$ but, in the winter, due to a lack of sunlight, the water vapour in the atmosphere is very limited and $\mathrm{OH}$ radicals are also very scarce. Under these conditions a sudden violent increase in $\mathrm{OH}$ radicals, due to solar protons, causes atmospheric chemical variations easy to detect.

During January (Fig. 3, top left) the mesospheric OH background concentration is about $1 \mathrm{ppbv}$ in the Northern Hemisphere (below $75 \mathrm{~km}$ ). When SEP events occur on 17 and 20 January a suggestive increase in $\mathrm{OH}$, more intense at elevated altitudes, is recorded. It is worthwhile to note that the $\mathrm{OH}$ concentration reaches the maximum intensity almost at the 

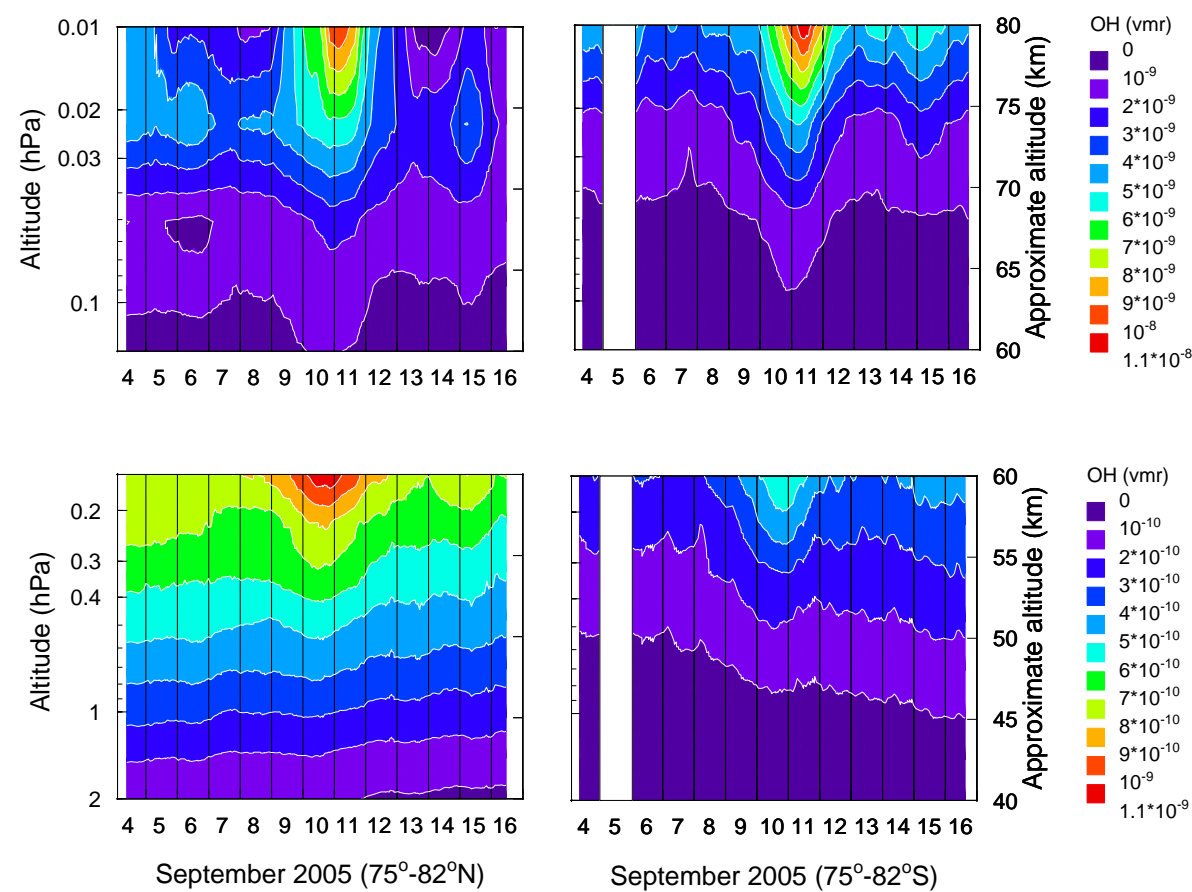

Fig. 5. Temporal evolution of averaged values $\left(\sim 75^{\circ}-82^{\circ} \mathrm{N}\right.$ and $\left.\mathrm{S}\right)$ of September $2005 \mathrm{OH}$ volume mixing ratio (vmr), approximately in mesosphere (top) and in upper stratosphere (bottom). The left column reports the Northern Hemisphere and the right the Southern one (see the caption of Fig. 2 for the correspondent SZA).

same time as the solar proton peaks (between 17 and 18 January and in late 20 January). The $\mathrm{OH}$ increase in the darker hemisphere is more intense and long lasting: at about $75 \mathrm{~km}$ the $\mathrm{OH}$ mixing ratio is $10 \mathrm{ppbv}$ and reaches almost $12 \mathrm{ppbv}$ at $80 \mathrm{~km}$ (provided that data are averaged and the $\mathrm{OH}$ peak is smoothed). In the upper stratosphere-low mesosphere a sudden rise of the hydroxyl radical is also visible (Fig. 3, bottom left). The $\mathrm{OH}$ background mixing ratio is very low (between 0.01 and $0.1 \mathrm{ppbv}$ ). Above $55 \mathrm{~km}$ the $\mathrm{OH}$ mixing ratio is almost 0.5 ppbv during the SEP event. Overall, the hydroxyl radical mixing ratio increases by almost one order of magnitude in the upper mesosphere (Fig. 3, top left) and 100-400\% (from lower altitudes to higher) in upper stratosphere (Fig. 3, bottom left).

The impact of the 20 January SEP event on the atmosphere is less intense but of the same order of magnitude both in the mesosphere and stratosphere.

In the summer hemisphere the $\mathrm{OH}$ background mixing ratio is noticeably higher and the variations connected to the SEP event are not very impressive and have a short length. In addition, the $\mathrm{OH}$ peak also occurs in the Southern Hemisphere at the same time (Fig. 3, top right).

It is interesting to see that during the SEP events the $\mathrm{OH}$ mixing ratio of the dark hemisphere is almost equal to the $\mathrm{OH}$ background of the day hemisphere.

It is possible to note that in the Northern Hemisphere the mesospheric $\mathrm{OH}$ rise starts on 16 January and finishes on
22 January, coinciding with the period of the strong ozone depletion. Because of the running average procedure performed on the MLS data set it is not trivial to estimate the delay between the $\mathrm{OH}$ rise and ozone depletion. We estimated a delay of approximately $12 \mathrm{~h}$ in the "night" hemisphere, whereas it is almost contemporary in the "day" hemisphere, where the photolysis is more active.

Figure 4 shows the $\mathrm{OH}$ mixing ratio for 14 May 2005. After the SEP event of 14 May the odd hydrogen species exhibit some changes. In the darker hemisphere (Fig. 4, right) the $\mathrm{OH}$ variations are not as large as in January but are still strong enough to destroy the third ozone maximum (see Fig. 2, middle right). Moreover, the increase seems to involve only the mesosphere. The reason maybe twofold: i) as noted in Sect. 3 the considered SEP event has a very low content of high energy particles that results in a smaller perturbation of the inferior atmospheric layers; ii) at low energies the fluence is smaller in comparison to the other analysed SEP events, although the peak value is similar.

The $\mathrm{OH}$ background mixing ratio for the Southern Hemisphere is roughly $1 \mathrm{ppbv}$ (below $75 \mathrm{~km}$ ), similar to that during January 2005 at the North side, but the maximum rise is only about $8 \mathrm{ppbv}$ (at $80 \mathrm{~km}$ ) instead of $12 \mathrm{ppbv}$. The effects of the solar protons on the odd hydrogen species are moderated in the summer hemisphere and the maximum rise happens roughly on 15 May for both hemispheres. 
The SEP event of 8 September 2005 occurs under different seasonal conditions. The interhemispheric variation of the solar illumination is not very large, as for the previous SEP events. The background of the mesospheric (stratospheric) $\mathrm{OH}$ mixing ratio is a few ppbv $(<0.1 \mathrm{ppbv})$ for both hemispheres. Its variability is more evident in the darker hemisphere (South), where, above $75 \mathrm{~km}$, a small rise is also discernible, due to a new moderate increase in the proton flux on 14 and 15 September. In addition, the increase in the odd hydrogen species, represented by the $\mathrm{OH}$ proxy, is apparent also in the stratosphere, at least up to $50 \mathrm{~km}$, where it becomes less evident since it is masked by the seasonal cycle.

\section{Discussion and conclusion}

We analysed several SEP events which occurred during 2005, looking for the ozone and $\mathrm{OH}$ responses. In spite of their somewhat weaker particle fluxes, if compared to other previous SEP events analysed (see the Introduction), they have been able to produce more intense variation in the mesospheric chemistry than in the stratospheric one. We found that SEP effects on the Earth's atmosphere are different on the night and day hemisphere at high latitudes $\left(75^{\circ}-82^{\circ}\right)$. In particular, the odd hydrogen species seem to be very sensitive to SEP fluxes.

We recall that the EOS MLS instrument on the AURA satellite recorded mesospheric $\mathrm{OH}$ (proxy for the odd hydrogen species) increases due to SEP events, for the first time, during the investigated periods. $\mathrm{No}_{\mathrm{HO}}$ data were available before 2005 SEP events in order to check the accuracy of the models related to mesospheric ozone destruction triggered by $\mathrm{HO}_{\mathrm{x}}$ components. We noted that, as expected, the response of odd hydrogen species to SEPs is very fast, almost contemporary, either in the summer or winter hemisphere. The higher mesospheric $\mathrm{OH}$ values under solar illumination make it difficult to detect the rise due to solar protons since the background concentration of hydrogen species depends on $\mathrm{H}_{2} \mathrm{O}$ concentration. On the contrary, reduced solar illumination makes it easier to observe atmospheric chemistry changes due to SEPs. Moreover, the $\mathrm{OH}$ changes are long lasting in the winter hemisphere with respect to the summer one (because of the shorter life under the solar light of $\mathrm{OH}$ components) but the affected altitudes are similar. Thus, the opposite terrestrial season does not influence the possibility of odd hydrogen species triggering catalytic cycles at specific altitudes, but only the percentage of variation and the duration.

The event of 17 January has the most intense flux at $>10 \mathrm{MeV}$ among the analysed SEP events, whereas the 20 January SEP is approximately similar to that of May and September at this energy range. Nevertheless, the mesospheric $\mathrm{OH}$ rise during September seems to reach an order of magnitude similar to the 17 January event, probably because of the comparable fluence of both events. The $\mathrm{OH}$ increase, due to the May SEP event, is less intense and its reason could be the smaller fluence of this event relative to the others.

Also the changes connected to ozone are different among the diverse events. The presence of a tertiary ozone peak in the winter mesosphere makes it easier to single out its decrease linked to the $\mathrm{HO}_{\mathrm{x}}$ rise. The destruction of the ozone peak is very clear on 18 January and the maximum percentage of destroyed $\mathrm{O}_{3}$ varies from $\sim 25 \%$ (at $\sim 55 \mathrm{~km}$ ) to $\sim 75 \%$ (at $\sim 70 \mathrm{~km}$ ). The slightly darker condition of the Southern Hemisphere favours the presence of a similar third ozone peak (even more intense) in May and its subsequent destruction during and after the solar particle event. The weak fluence of $>10 \mathrm{MeV}$ particles leads to $\mathrm{O}_{3}$ depletion (on $16 \mathrm{May}$ ) at $\sim 60 \mathrm{~km} \mathrm{(10 \% )} \mathrm{that} \mathrm{reaches} 45 \%$ at $\sim 70 \mathrm{~km}$. The ozone depletion in the summer hemisphere is negligible for both SEP events.

The higher solar illumination in September in the Southern Hemisphere induces depletion also in the stratosphere. The $\mathrm{O}_{3}$ decrease on 10 September seems to start at $\sim 40 \mathrm{~km}$ of altitude and becomes greater than $\sim 20 \%$ at $\sim 45 \mathrm{~km}$. It is connected with the $\mathrm{NO}_{\mathrm{x}}$ rise, and more active in the stratosphere. Anyway, the depletion in the mesosphere is not as intense as that for the 17 January SEP event. In fact, the MLS instrument recorded a decrease of only $\sim 40 \%$ at $70 \mathrm{~km}$ (more intense above this height). Note also the stratospheric ozone decrease above $40 \mathrm{~km}$ in the day hemisphere on 10 and 11 September. Odd nitrogen species could cause ozone depletion again.

We conclude that even SEP events characterised by lower fluxes strongly affect the mesospheric chemistry at elevated latitudes and their impact is different in the night and day hemispheres. Moreover, when different SEP events have comparable maximum flux values, the most relevant SEP feature is its fluence. In particular, the greater the fluence at $>10 \mathrm{MeV}$, the more important the SEP effects are. Furthermore, SEPs with low content of high energy particles result in a smaller perturbation of the lower atmospheric layers. Seasonal conditions are also essential to spread SEP influence on the stratosphere.

Acknowledgements. Work partly performed for a $\mathrm{PhD}$ thesis under development at Siena University - Dept. of Earth Science. This research topic is faced for COST 724 Action and supported by the Antarctic Research Program of Italy in the frame of Science for Solar-Terrestrial Relations. Thanks are due to the PIs of the different experiments from which we have taken the data and the corresponding Data Centers and Services.

Topical Editor U.-P. Hoppe thanks two anonymous referees for their help in evaluating this paper. 


\section{References}

Canty, T., Pickett, H. M., Salawitch, R. J., et al.: Stratospheric and mesospheric HOx: Results from Aura MLS and FIRS-2, Geophys. Res. Lett., 33, L12802, doi:10.1029/2006GL025964, 2006.

Crutzen, P. J., Isaksen, I. S. A., and Reid, G. C.: Solar proton events: Stratospheric source of nitric oxide, Science, 189, 457458, 1975.

Crutzen, P. J.: Mesospheric Mysteries, Science, 277, 1951-1952, 1997.

Damiani, A., Storini, M., Laurenza, M., et al.: Southern ozone variations induced by solar particle events during 15 January- 5 February 2005, J. Atmos. Sol.-Terr. Phys., 68, 2042-2052, 2006.

Degenstein, D. A., Gattinger, R. L., Lloyd, N. D., et al.: Observations of an extended mesospheric tertiary ozone peak, J. Atmos. Sol.-Terr. Phys., 67, 1395-1402, 2005.

Froidevaux, L., Livesey, N. J., Read, W. G., et al.: Early Validation Analyses of Atmospheric Profiles from EOS MLS on the Aura Satellite, IEEE TGARS, 44, doi:10.1109/TGRS.2006.864366, 2006.

Hervig, M., Mchugh, M., and Summers, M.: Water vapour enhancement in the polar summer mesosphere and its relationship to polar mesospheric clouds, Geophys. Res. Lett., 30, 20, ASC5.1ASC5.5, 2003.

Jackman, C. H., Cerniglia, M. C., Nielsen, J. E., et al.: Twodimensional and three-dimensional model simulations, measurements, and interpretation of the October 1989 solar proton events on the middle atmosphere, J. Geophys. Res., 100, 11 641-11 660, 1995.

Jackman, C. H., McPeters, R. D., Labow, G. J., et al.: Northern Hemisphere atmospheric effects due to the July 2000 solar proton event, Geophys. Res. Lett., 28, 2883-2886, 2001.

Jackman, C. H., DeLand, M. T., Labow, G. J., et al.: Neutral atmospheric influences of the solar proton events in October-November 2003, J. Geophys. Res., 110, A09S27, doi:10.1029/2004JA010888, 2005.

Krivolutsky, A. A., Klyuchnikova, A. V., Zakharov, G. R., et al.: Dynamical response of the middle atmosphere to solar proton event of July 2000: Three-dimensional model simulations, Adv. Space Res., 37, 1602-1613, 2006.

Lary, D. J.: Catalytic destruction of stratospheric ozone, J. Geophys. Res., 102, 21 515-21 526, 1997.

Laurenza, M., Hewitt, J., Storini, M., et al.: Solar energetic proton events and soft X-ray flares, 20th ECRS Proceedings, http: //www.lip.pt/events/2006/ecrs/proc/, 2007.

Livesey, N. J., Read, W. G., Filipiak, M. J., et al.: Earth Observing System (EOS) Microwave Limb Sounder (MLS) Version 1.5 Level 2 data quality and description document, JPL D-32381, Version 1.51, Jet Propulsion Laboratory, California Institute of Technology, Pasadena, California, 2005.

López-Puertas, M., Funke, B., Gil-López, S., et al.: Observation of $\mathrm{NO}_{x}$ enhancement and ozone depletion in the Northern and Southern Hemispheres after the October-November 2003 solar proton events, J. Geophys. Res., 110, A09S43, doi:10.1029/2005JA011050, 2005a.
López-Puertas, M., Funke, B., Gil-López, S., et al.: $\mathrm{HNO}_{3}$, $\mathrm{N}_{2} \mathrm{O}_{5}$, and $\mathrm{ClONO}_{2}$ enhancements after the October-November 2003 solar proton events, J. Geophys. Res., 110, A09S44, doi:10.1029/2005JA011051, 2005b.

Marsh, D., Smith, A., Brasseur, G., et al.: The existence of a tertiary ozone maximum in the high-latitude middle mesosphere, Geophys. Res. Lett., 28, 4531-4534, 2001.

Orsolini, Y. J., Manney1, G. L., Santee, M. L., and Randall, C. E.: An upper stratospheric layer of enhanced HNO3 following exceptional solar storms, Geophys. Res. Lett., 32, L12S01, doi:10.1029/2004GL021588, 2005.

Pickett, H. M., Drouin, B. J., Canty, T., et al.: Validation of Aura MLS HOx measurements with remotesensing balloon instruments, Geophys. Res. Lett., 33, L01808, doi:10.1029/2005GL024442, 2006.

Reagan, J. B., Meyerott, R. E., Nightingale, R. W., et al.: Effects of the August 1972 solar particle events on stratospheric ozone, J. Geophys. Res., 86, 1473-1494, 1981.

Reid, G. C., Solomon, S., and Garcia, R. R.: Response of the middle atmosphere to the solar proton events of August-December, 1989, Geophys. Res. Lett., 18, 1019-1022, 1991.

Rohen, G., von Savigny, C., Sinnhuber, M., et al.: Ozone depletion during the solar proton events of October/November 2003 as seen by SCIAMACHY, J. Geophys. Res., 110, A09S39, doi:10.1029/2004JA010984, 2005.

Schoeberl, M. R., Douglass, A. R., Hilsenrath, E., et al.: Overview of the EOS aura mission, IEEE TGARS, 44, 1066-1074, 2006.

Seppälä, A., Verronen, P. T., Kyrölä, E., et al.: Solar proton events of October-November 2003: Ozone depletion in the Northern Hemisphere polar winter as seen by GOMOS/Envisat, Geophys. Res. Lett., 31, L19107, doi:10.1029/2004GL021042, 2004.

Seppälä, A., Verronen, P. T., Sofieva, V. F., et al.: Destruction of the tertiary ozone maximum during a solar proton event, Geophys. Res. Lett., 33, L07804, doi:10.1029/2005GL025571, 2006.

Solomon, S., Rusch, D. V., Gérard, J.-C., et al.: The effect of particle precipitation events on the neutral and ion chemistry of the middle atmosphere: II odd hydrogen, Planet. Space Sci., 29, 885-892, 1981a.

Solomon, S. and Crutzen, P. J.: Analysis of the August 1972 solar proton event including chlorine chemistry, J. Geophys. Res., 86, 1140-1146, 1981b.

Solomon, S., Reid, G. C., Rusch, D. W., and Thomas, R. J.: Mesospheric ozone depletion during the solar proton event of July 13, 1982 PART II. Comparisons between theory and measurements, Geophys. Res. Lett., 10, 257-260, 1983.

Verronen, P. T., Seppälä, A., Clilverd, M. A., et al.: Diurnal variation of ozone depletion during the October-November 2003 solar proton events, J. Geophys. Res., 110, A09S32, doi:10.1029/2004JA010932, 2005.

Verronen, P. T., Seppälä, A., Kyrölä, E., et al.: Production of odd hydrogen in the mesosphere during the January 2005 solar proton event, Geophys. Res. Lett., 33, L24811, doi:10.1029/2006GL028115, 2006.

Waters, J. W., Froidevaux, L., Harwood, R. S., et al.: The Earth Observing System Microwave Limb Sounder (EOS MLS) on the Aura satellite, IEEE TGARS, 44, 1075-1092, 2006. 